\title{
A tétrade de Mcluhan na pesquisa em comunicação: revisão sistemática de aplicações no Brasil e em Portugal
}

The McLuhan's tetrad in communication research: systematic review of applications in Brazil and Portugal

\author{
CAROLINA WEBER DALL'AGNESEa \\ Universidade Federal de Santa Maria, Programa de Pós-Graduação em Comunicação. Santa Maria - RS, Brasil \\ J O ÃO CANAVILHA S \\ Universidade da Beira Interior, Departamento de Comunicação, Filosofia e Política. Covilhã, Portugal \\ EUGENIA MARIA MARIANO DA ROCHA BARICHELLOc \\ Universidade Federal de Santa Maria, Programa de Pós-Graduação em Comunicação. Santa Maria - RS, Brasil
}

\section{RESUMO}

O artigo apresenta os resultados de um trabalho exploratório para mapear a aplicação da tétrade de McLuhan em pesquisas da área da comunicação no Brasil e em Portugal. A metodologia usada foi a revisão sistemática da literatura publicada na última década (2009-2019). Para tal mapeamento, trabalhos acadêmicos (teses, dissertações, artigos e capítulos) foram localizados a partir de sistemas de indexação, repositórios públicos e motores de busca especializados. O objetivo foi descobrir como a tétrade vem sendo aplicada e a que objetos. Por fim, são apontadas potencialidades da ferramenta, chamada por McLuhan de "sonda exploratória".

Palavras-chave: Revisão sistemática, tétrade de McLuhan, leis da mídia, ecologia da mídia

\section{ABSTRACT}

This article presents the results of an exploratory work to map the application of McLuhan's tetrad, in communication studies in Brazil and Portugal. The methodology used was the systematic review of the literature in the last decade (2009-2019). For such mapping, academic works (theses, dissertations, articles and chapters) were located from indexing systems, public repositories and specialized search engines. The goal was to discover how the tetrad has been applied and to which purposes. Finally, the potentialities of this tool, called McLuhan's “exploratory probe", are pointed out.

Keywords: Systematic review, McLuhan's tetrad, laws of media, media ecology

${ }^{a}$ Jornalista, doutoranda em Comunicação na Universidade Federal de Santa Maria e em Ciências da Comunicação na Universidade da Beira Interior (regime de cotutela). Orcid: https://orcid.org/00000003-1401-7500. E-mail: caroltweber@gmail.com

${ }^{\mathrm{b}}$ Professor na Universidade da Beira Interior (UBI) e pesquisador no Labcom.IFP - Comunicação, Filosofia e Humanidades. Orcid: https:// orcid.org/0000-0002-2394-5264. E-mail: jcanavilhas@gmail.com

' Professora do Programa de Pós-Graduação em Comunicação da Universidade Federal de Santa Maria (UFSM). Líder do Grupo de Pesquisa em Comunicação Institucional e Organizacional (CNPq). Orcid: http://orcid.org/00000001-5244-2829. E-mail: eugeniabarichello@gmail.com 


\section{INTRODUÇÃO}

E BUSCARMOS O perfil criado para Herbert Marshall McLuhan (1911-1980) no Google Acadêmico (https://bit.ly/2Z4SABI), encontraremos um número de mais de 83.700 citações desde 1995 até agora. No topo da lista de obras citadas figura Understanding media: The extensions of man, publicado originalmente em 1964. Trata-se do quinto livro do canadense, considerado um dos textos (ou antitextos) essenciais para os estudos da comunicação

${ }^{1}$ Explica Meyrowitz (2003) que, ao final dos anos 1970, "muitos de seus termos ainda ecoavam nas arenas populares, mas poucos que os usavam pareciam entender seu significado ou implicações. E nas arenas acadêmicas, suas ideias foram virtualmente banidas. No final da década de 1980, Understanding media e a maioria de seus outros livros estavam esgotados e fora de catálogo. Além disso, os acadêmicos que tentaram publicar trabalhos sobre ou a partir dos frameworks de McLuhan, frequentemente encontravam resistência por parte de revisores" (p. 205). No original: "Many of his terms still echoed in popular arenas, yet few who used them seemed to grasp their meaning or implications. And in scholarly arenas, his ideas were virtually banished. By the end of the 1980s, Understanding Media and most of his other books were out of print. Moreover, scholars who tried to publish works about, or built on, McLuhan's frameworks often ran into resistance from peer-reviewer". Esta e demais traduções dos autores.

${ }^{2}$ No original: "Although change incomplete and sometimes baffling, McLuhan's writing stands out from that of almost all his contemporaries as pointing clearly to dramatic structural changes in society and world affairs: changes in our experience of time and space, in borders and

boundaries, in sensibilities concerning public and private, in categories of media content".
(Meyrowitz, 2003). Ao longo de sua carreira, McLuhan conquistou tanto seguidores quanto críticos. Polêmico nos anos 1960 e 1970 e lançado ao ostracismo pela academia na década de $1980^{1}$, suas ideias foram recuperadas e ganharam ainda mais força no novo milênio, à medida que muitos de seus escritos tomaram a forma de previsões.

Embora incompleta e às vezes desconcertante, a escrita de McLuhan se destaca da de quase todos os seus contemporâneos ao apontar claramente para mudanças estruturais dramáticas na sociedade e nos assuntos mundiais: mudanças em nossa experiência de tempo e espaço, em fronteiras e limites, em sensibilidades relativas ao público e privado, em categorias de conteúdo de mídia². (Meyrowitz, 2003, p. 209)

Uma ideia em particular de Understanding media se destaca: a chamada para prestarmos atenção às formas com que as tecnologias criadas pelos seres humanos também atuam para moldá-los ou transformá-los, ao gerarem ambientes $^{3}$ para a ação, pensamento e percepção (Meyrowitz, 2003). Esse seria um dos significados contidos na frase "O meio é a mensagem". Assim, para compreendermos o impacto das tecnologias nas sociedades, devemos nos mover da análise linear dos conteúdos para uma observação holística dos efeitos mais gerais dos meios - esses entendidos como quaisquer artefatos que ampliam ou estendem as faculdades humanas, os corpos e consciências de quem os utiliza.

Compreender os efeitos gerais e o funcionamento de um meio em dado contexto espaçotemporal passa pelo exercício de perceber a relação figura/ fundo. Para McLuhan e Powers (1989/1992), todas as situações culturais são compostas por uma área de atenção (figura) e uma área de desatenção (fundo) $)^{4}$, esta última muito mais abrangente. O fundo é o ambiente que "fornece a estrutura ou o estilo da consciência, a forma de ver ou os termos nos quais a figura é percebida"5 (p. 5). Pode ser interpretado como o contexto no qual um meio, uma tecnologia, uma organização, uma instituição ou um corpo de ideias atua e está situado e no qual transforma e/ou é transformado.

Devido a esse caráter ambiental e subliminar, estudar o fundo é um desafio. Para McLuhan (1964/2007, 2005), normalmente apenas há uma consciência das 
figuras, e só se percebe um ambiente quando este é substituído por outro. $\mathrm{O}$ único antídoto seria a construção de um antiambiente, função a ser desempenhada pelo artista, a "única pessoa na cultura cujo negócio é a reciclagem e atualização da sensibilidade"6 (McLuhan \& Powers, 1989/1992, pp. 5-6). Mas também seria possível através do exercício reflexivo de investigação e estudo dos meios.

Para possibilitar essa tarefa, McLuhan constrói, em seus últimos anos de vida, um instrumento que propõe revelar figura e fundo, simultaneamente, a partir do reconhecimento do conjunto de padrões de processos referentes a uma tecnologia ou artefato. Trata-se da tétrade dos efeitos, uma teoria desenvolvida em duas obras: os livros Laws of media: The new science (McLuhan \& McLuhan, 1988) e The global village: Transformations in world life and media in the 21st century (McLuhan \& Powers, 1989/1992) ${ }^{7}$. Apontada como uma ferramenta flexível que se adapta a contextos diversos de pesquisa, a tétrade sintetiza e torna operacionalizáveis as afirmações mais instigantes de Understanding media, a partir da formulação de quatro leis (ou princípios científicos) a que todo meio estaria submetido.

A partir da curiosidade de verificar como a tétrade de McLuhan é apropriada por pesquisadoras e pesquisadores em comunicação no Brasil e em Portugal, este artigo apresenta os resultados de um trabalho exploratório para mapear a aplicação do modelo na última década (2009-2019). A estratégia de pesquisa foi a revisão sistemática da literatura (Kitchenham, 2004; Petticrew \& Roberts, 2006). Como fontes de dados, foram incluídos trabalhos acadêmicos (teses, dissertações, artigos e capítulos de livros) localizados a partir de repositórios públicos, sistemas de indexação e motores de busca especializados.

O objetivo da investigação foi descobrir como a tétrade vem sendo aplicada, a que objetos (teóricos, empíricos) e se o modelo é problematizado nas investigações (pesquisas discutem seus potenciais e limites?). Ao longo da revisão, destacaram-se outros aspectos, como a variação de traduções na sua nomenclatura (e.g., método tetrádico, tetraedro, tétrades dos efeitos midiais...) e de seus quatro componentes.

Esta revisão espera contribuir para apoiar futuras pesquisas que possam adotar a tétrade de McLuhan como ferramenta de investigação, em especial aquelas que incluem a ecologia da mídia como base teórica para estudar produtos, processos e práticas de comunicação midiática sempre em relação ao ecossistema midiático contemporâneo.

\section{AS LEIS DA MÍDIA E A TÉTRADE DE MCLUHAN}

As quatro leis da mídia representadas na tétrade foram elaboradas após um intenso trabalho de revisão de Understanding media empreendido por Marshall e Eric McLuhan ${ }^{8}$, a fim de encontrar afirmações que pudessem ser testadas, provadas
${ }^{3}$ De forma geral, um ambiente é um complexo sistema que influencia as formas como sentimos, pensamos e agimos a partir de códigos e regras mais ou menos implícitas. McLuhan (1964/2007) chama atenção para o entendimento com a frase "o meio é a mensagem" nas primeiras páginas de Understanding media: "cada tecnologia cria, gradualmente, um ambiente humano totalmente novo. Os ambientes não são envoltórios passivos, mas processos ativos" (pp. vi-vii, prefácio).

${ }^{4}$ Os termos figura e fundo foram inspirados na psicologia Gestalt (McLuhan \& Powers, 1989/1992).

${ }^{5}$ No original: "ground provides the structure of or style of awareness, the way of seeing or the terms on which a figure is perceived".

${ }^{6}$ No original: "the only person in the culture whose whole business is the retraining and updating of sensibility".

${ }^{7}$ Ambos publicados após a morte de McLuhan.

${ }^{8}$ Laws of media: The new science, sem edição em língua portuguesa, foi publicado em 1988 após a morte de Marshall McLuhan (1980). Conforme explicou Eric McLuhan, a elaboração da forma tetrádica foi uma resposta aos críticos do pai acerca da ausência de cientificidade de Understanding media (McLuhan \& McLuhan, 1988). 
${ }^{9}$ Para McLuhan, medium é um conceito amplo, que se confunde com tecnologia, e compreende qualquer artefato que amplia ou estende as faculdades humanas, os corpos e a consciência de quem os utiliza. Não só a televisão, o rádio, o computador, mas o martelo, a roda, o dinheiro e o avião também são meios. A roda seria uma extensão do pé; o rádio, a extensão que leva a voz a grandes distâncias. A escrita estende a voz ou o discurso. A linguagem, uma tecnologia que estende todos os sentidos humanos, simultaneamente. Todos representam, ao mesmo tempo, amputações, pois quando um meio amplifica um sentido ou faculdade humana, também o adormece. A agenda eletrônica estende a capacidade e volume de armazenamento de informações e compromissos para além do que se poderia mensurar; porém, com o tempo, também amputa as habilidades naturais de memorização. Portanto, na adoção das tecnologias/extensões, seres humanos são permanentemente modificados (nas formas com que interagem, percebem e interpretam o mundo) e também modificam (a partir da ação) o ambiente ao redor e as próprias tecnologias.

${ }^{10}$ No original: "We found that everything man makes and does, every procedure, every style, every artifact, every poem, song, painting, gimmick, gadget, theory, technology - every product of human effort - manifested the same four dimensions".

${ }^{11}$ Forma, meio, artefato e tecnologia são as unidades de análise da tétrade, conforme as obras supracitadas. ou refutadas por qualquer pessoa, em qualquer lugar e a qualquer tempo. Noutros termos, que pudessem ser apresentadas enquanto princípios científicos.

O desenvolvimento das leis da mídia levou em conta a noção alargada que McLuhan tinha acerca do meio 9 . Seriam, portanto, aplicáveis a qualquer tecnologia ou artefato, seja hardware (por exemplo, uma caneta, um computador) ou software (uma proposição, uma lei científica), a qualquer palavra ou frase, em qualquer linguagem. Para os autores, "tudo que o homem faz e constrói, cada procedimento, cada estilo, cada artefato, cada poema, música, pintura, truque, dispositivo, teoria, tecnologia - cada produto do esforço humano - manifesta essas quatro dimensões"10 (McLuhan \& McLuhan, 1988, p. ix).

As leis da mídia que embasam a construção das tétrades são elaboradas como questões em relação ao objeto de análise:

- Aprimoramento (enhancement): como uma extensão humana, toda tecnologia estende ou amplifica algum órgão ou faculdade do usuário. $\mathrm{O}$ que o meio/artefato/forma ${ }^{11} \mathrm{em}$ análise aprimora, intensifica, torna possível ou acelera?

- Recuperação (retrieval): que ações, serviços e características de ambientes anteriores retornam ou são recuperados pelo novo meio/artefato/ forma? Qual antigo contexto (ou fundo, ground) é trazido de volta e é inerente a este?

- Obsolescência (obsolescence): quando uma área de experiência é realçada ou intensificada, outra é diminuída ou paralisada. Que condição anterior é afastada do foco das atenções ou obscurecida pelo novo meio/artefato/forma?

- Reversão (reversal): quando levado aos limites do seu potencial, um meio/artefato/forma tende a uma reversão de suas características originais. O que é produzido ou no que o meio/artefato/forma se torna quando levado a um extremo? Ou, qual é o potencial de reversão do objeto em análise?

Para cada uma dessas questões, não há apenas uma única resposta correta. Explica Eric McLuhan, em trabalho mais recente no qual resgata a construção da ferramenta, que "todas as respostas precisas são respostas corretas. Quando você tem uma clara resposta a qualquer uma das faces, pergunte 'o que mais?"' (McLuhan \& McLuhan, 2017, p. 7). Tal observação destaca o caráter de "sonda exploratória" do método. Isso porque, conforme os McLuhan, o exercício é especialmente propício para compreender situações em processo, de (re)estruturação de percepções ou ambientes (McLuhan \& McLuhan, 1988). Nota-se, ainda, que 
não há relação hierárquica entre os quatro aspectos: todos são observados de forma simultânea, pois são inerentes ao objeto em análise desde o início.

Aprimoramento, que tem a ver com o aperfeiçoamento das habilidades humanas, relaciona-se diretamente com a obsolescência, uma vez que, ao realçar a função ou funções de um meio/tecnologia/artefato, o que veio antes é obscurecido ou diminuído. Ao mesmo tempo, aperfeiçoar algo já existente implica a recuperação de uma forma do passado. E o que é recuperado não são apenas funções ou propriedades específicas, mas elementos de ambientes de mídia anteriores que assumem nova forma. Uma vez que o ecossistema midiático se encontra em permanente transformação por meio das relações de equilíbrio, desequilíbrio e reequilíbrio entre as espécies que o compõem (Canavilhas, 2010), por mais que se resgatem "velhos" meios, os ambientes gerados nunca terão as mesmas características, já que, em um diferente contexto (fundo), distintas relações são efetivadas.

No caso da reversão, Logan (2011) explica que "quando levado suficientemente longe, o novo meio/tecnologia/artefato feito pelo Homem se inverte, dá uma reviravolta, tornando-se uma forma complementar ou possivelmente oposta" (p. 7). Contudo, essa oposição não é absoluta, como contrapõe Levinson (1999), já que a reversão expressa continuidade de elementos que, antes obscurecidos, são recuperados. O autor exemplifica:

O rádio, por exemplo, amplifica a voz humana instantaneamente através de vastas distâncias para uma audiência massiva. Ele torna obsoleta a imprensa como um meio de comunicação de massa, quando, por exemplo, nós recebemos as primeiras informações de um evento noticioso importante pelo rádio em vez de uma edição "extra" de um jornal. Ele recupera o "arauto", que foi tornado obsoleto, em grande parte, pela impressão. E o rádio acústico, quando pressionado até o seu limite, reverte-se em televisão audiovisual ${ }^{12}$. (pp. 189-190)

Remetendo para a noção de meio como ambiente/extensão, McLuhan e McLuhan (1988) salientam que o objeto de análise da tétrade nunca é neutro ou passivo, mas uma expressão ativa da mente e do corpo humano que transforma tanto quem o utiliza como o seu entorno. A tétrade, portanto, é uma representação desses quatro processos simultâneos, holísticos e inerentes a qualquer meio/ tecnologia/artefato. Graficamente, é representada por uma fita de Möbius, uma superfície topológica unilateral com as extremidades unidas, a qual representa um caminho sem fim ou início (Figura 1). A intenção de McLuhan ao selecionar essa topologia foi "expressar a persistente e tênue relação de alteração dos padrões de processo da tétrade"13 (McLuhan \& Powers, 1989/1992, p. 182).
${ }^{12}$ No original: "Radio, for example, amplifies the human voice instantly across vast distances to a mass audience. It obsolesces print as a mass medium, as when, for example, we receive our first word of an important news event on radio rather than via an 'extra' addition of a newspaper. It retrieves the town crier, who had been obsolesced to a large extent by print. And acoustic radio, when pushed to its limits, reverses into audiovisual television".

${ }^{13}$ No original: "Marshall McLuhan thought that such a typology, as a new intellectual emblem, might be useful in expressing the persistently tently altering relationship of the tetrad's process patterns". 


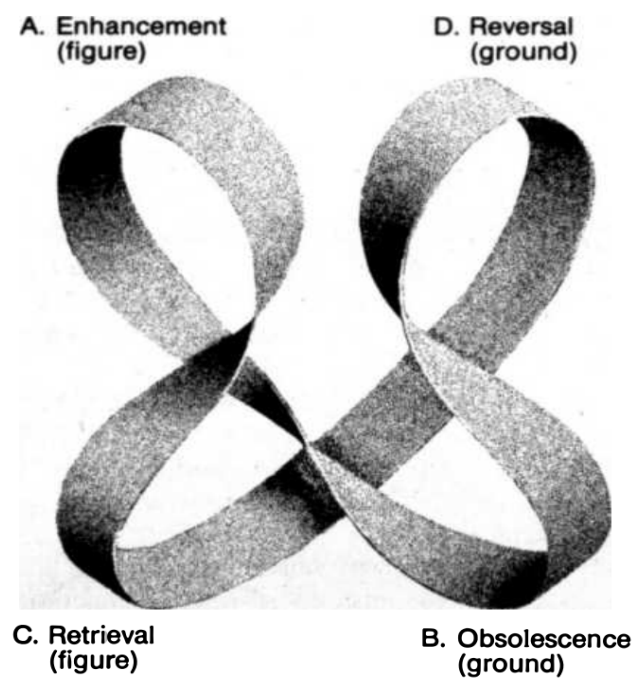

Figura 1. Estrutura da tétrade. Reproduzida do livro The global village: Transformations in world life and media in the 21st century (McLuhan \& Powers, 1989/1992).

Segundo os autores, o reconhecimento de padrões por meio do modelo tetrádico tem o potencial de revelar aspectos inicialmente invisíveis do meio/ tecnologia/artefato para a percepção humana. Para isso, esse exercício requer observação cuidadosa do artefato em relação a seu fundo, em vez de considerações abstratas (McLuhan \& Powers, 1989/1992). Desta forma, a tétrade atua como antiambiente, evidenciando figura e fundo simultaneamente.

No que concerne à obsolescência, conforme explica Logan (2011):

O meio que amplia alguma função humana e é tema da primeira lei é a figura. $\mathrm{O}$ meio que sofre obsolescência e o meio que é recuperado são o fundo. E o novo meio que o meio da primeira lei se torna é a nova figura. (p. 8)

Alterações nos fundos modificam as figuras, e vice-versa. McLuhan e Powers (1989/1992) acrescentam que o próprio contexto do usuário também funciona como fundo na construção da tétrade:

A tétrade não apenas revela o caráter configuracional do tempo, mas também que o artefato (ou ideia fundadora) é sempre produto da mentalidade do usuário. A tétrade inclui o fundo [ground] do usuário como enunciador; e, paradoxalmente, inclui o usuário como fundo.... Por exemplo, em geral, uma análise dos efeitos da palavra impressa em diferentes 
ambientes usualmente gera resultados bastante diferentes. As tétrades da imprensa nos Estados Unidos, China ou África apresentariam três diferentes fundos ${ }^{14}$. (pp. 201-202)

A aplicação do método tetrádico pode resultar em uma ou em um grupo de tétrades interconectadas. Qualquer uma das faces da tétrade pode inspirar um novo mapeamento de quatro partes; quanto mais se debruça sobre as primeiras análises, mais conexões são feitas, pois os quatro efeitos da tétrade são raramente singulares (Levinson, 1999). Isso porque cada meio realça, obscurece, resgata e reverte-se em mais de uma coisa. Da mesma forma, meios diferentes podem realçar, obscurecer, resgatar ou reverter-se às mesmas coisas. Por exemplo, a televisão resgata a visualidade que o rádio obscurece. "E ao fazê-lo, a televisão no que o rádio se converteu - obscurece o rádio puramente acústico"15 (p. 191).

Nesse sentido, a aplicação do modelo tetrádico exige um esforço de olhar simultaneamente para o passado (aos contextos que levaram à criação de certo meio, tecnologia), para o presente (aos usos, apropriações e relações propiciadas pelas potencialidades e restrições do objeto analisado) e para um possível futuro (a partir da identificação de processos em curso, seja de aperfeiçoamento, obsolescência, recuperação ou reversão). Pela complexidade que envolve, a tétrade não pode resultar de um trabalho apressado, pois trata-se de um desafio para envolver o intelecto e a imaginação na busca por compreender os efeitos latentes da mídia no cotidiano (Levinson, 1999).

\section{QUESTÕES DE INVESTIGAÇÃO E METODOLOGIA}

O objetivo desta pesquisa é verificar como a tétrade de McLuhan é aplicada, e a que objetos (empíricos ou teóricos), nas pesquisas em comunicação desenvolvidas na última década (2009-2019) no Brasil e em Portugal. A partir deste mapeamento pretende-se apontar potencialidades e limitações da ferramenta, referida por McLuhan e Powers (1989/1992) como "uma sonda exploratória". Com esses propósitos, a metodologia empregada é a revisão sistemática da literatura (Kitchenham, 2004; Petticrew \& Roberts, 2006).

De acordo com Petticrew e Roberts (2006), revisões sistemáticas são revisões de literatura que adotam um conjunto de métodos específicos e que tentam identificar, avaliar e sintetizar todos os estudos relevantes a fim de responder a uma questão ou a um conjunto de questões. A busca da bibliografia envolve fontes abrangentes (trabalhos publicados ou em andamento, teses, artigos, resumos etc.) e uma estratégia de pesquisa explícita a fim de minimizar o erro sistemático ou os vieses. Por isso, as revisões sistemáticas são "menos uma discussão da literatura e mais uma ferramenta científica"16 (p. 10) e podem ser replicadas.
${ }^{14}$ No original: "The tetrad not only reveals the configurational character of time, but also that the artifact (or founding idea) is always the product of the user's mentality. The tetrad includes the ground of the user, as utterer; and paradoxically, includes the user as ground. We make ourselves and what we make is perceived as reality. For example, ample, an analysis of the effects of the printed word on another environment usually engenders quite different results. The tetrads for print in the United States, China, or Africa would have three different grounds".

${ }^{15}$ No original: "And in so doing, television - what radio has flipped into - obsolesces the purely acoustic radio".
${ }^{16}$ No original: "It is less of a discussion of the literature, and more of a scientific tool". 
Para Kitchenham (2004), empreender uma revisão sistemática é útil para tirar conclusões gerais sobre fenômenos (mais do que seria possível a partir de estudos individuais) e para basear atividades futuras de pesquisa. A autora identifica três fases principais: (1) planejamento, (2) condução e (3) escrita do relatório.

A primeira fase - planejamento - envolve a elaboração clara do que pesquisar e como fazê-lo. Neste trabalho, a questão de pesquisa é a seguinte:

- Como é aplicada a tétrade de McLuhan na pesquisa em comunicação no Brasil e em Portugal?

A partir desta questão geral surgem três novas interrogações:

- A que objetos (teóricos, empíricos) é aplicada?

- Há discussão acerca da tétrade enquanto ferramenta de pesquisa nas pesquisas identificadas?

- São apontadas potencialidades e limitações pelos autores? Se sim, quais?

A partir da definição das questões é delineado o protocolo, o qual descreve todo o processo e os métodos a serem aplicados. Inclui detalhes de como os diferentes estudos serão localizados, avaliados e sintetizados, bem como a sua divulgação (Petticrew \& Roberts, 2006).

Assim, quanto às estratégias para a busca, seleção e avaliação dos estudos, ver Tabela 1.

Tabela 1

Protocolo de pesquisa de revisão sistemática da literatura

\begin{tabular}{ll}
\hline Tipos de estudo a & - Artigos publicados em anais de eventos científicos e periódicos \\
serem localizados & - Teses \\
& - Dissertações \\
& - Capítulos de livro \\
Fontes de dados & - Repositórios de teses e dissertações: Banco de Dissertações e Teses \\
& e Catálogo de Teses e Dissertações da Capes (Brasil) e Repositórios \\
& Científicos de Acesso Aberto de Portugal (Portugal) \\
& - Ferramenta de pesquisa especializada: Google Scholar \\
& - Serviços de indexação: Web of Science; SciELO; Portal de Periódicos \\
& da Capes; B-On; Porbase (Biblioteca Nacional de Portugal) \\
& - Outros: não referenciados nos locais acima; inclui pesquisa nas \\
& referências bibliográficas dos trabalhos selecionados \\
& - Português \\
Idioma & -2009 a 2019 \\
Período & - tétrade AND McLuhan \\
Palavras-chave & - tetrádico AND McLuhan \\
& - tetrádica AND McLuhan \\
& - tetraedro AND McLuhan
\end{tabular}


Tabela 1

Continuação

Critérios de inclusão e exclusão

- Autoria: produção por pesquisadores vinculados a universidades/ organizações de ensino e pesquisa do Brasil e Portugal

- Área: (grande área) ciências sociais aplicadas; (área) comunicação e subáreas (conforme Conselho Nacional de Desenvolvimento Científico e Tecnológico/ Coordenação de Aperfeiçoamento de Pessoal de Nível Superior). Na ausência de filtros de busca ou da clara filiação dos autores, são consideradas as publicações em eventos ou periódicos de comunicação

- Aplicação: excluem-se os trabalhos que não apresentam uma aplicação efetiva da tétrade

A fase de condução engloba a seleção preliminar dos estudos, a avaliação da qualidade dos trabalhos, a extração dos dados e a síntese.

Sobre essa fase, esta revisão seguiu a seguinte ordem:

1. Pesquisa inicial a partir das palavras-chave. Utilizaram-se, também, filtros de busca, quando disponíveis, com base nos critérios de inclusão/exclusão (e.g., período, grande área, área).

2. Seleção preliminar dos trabalhos. A partir da análise das palavras-chave e resumos, fez-se uma seleção preliminar dos trabalhos potencialmente relevantes. Os arquivos PDF foram salvos em pastas no computador, inicialmente organizados por base de dados.

3. Refinamento dos resultados quantas vezes for necessário. Envolveu a análise dos textos completos salvos no passo anterior. Foram removidos os que não atenderam aos critérios de inclusão, especialmente quanto à efetiva aplicação da tétrade. Também foram excluídos nesta etapa textos duplicados e traduções de textos originais em outras línguas.

4. Leitura dos trabalhos, consolidação da lista definitiva e extração dos dados. A fim de responder às questões de pesquisa e identificar outras informações relevantes, os trabalhos selecionados tiveram os dados de interesse tabulados em planilhas eletrônicas. Foram preenchidos os seguintes itens: título; autoria; ano; tipo de trabalho; país; universidade/programa/periódico/evento/livro; etapa da pesquisa em que a tétrade é aplicada e (possíveis) justificativas para o uso; traduções (do modelo e das quatro faces); objeto(s) de aplicação; potenciais e limites apontados; resumo; e link do trabalho. Novamente foram excluídos textos duplicados e que não se encaixavam nos critérios da investigação, não detectados na fase anterior. Chegou-se a uma lista de 21 trabalhos para apreciação crítica. 
5. Apreciação crítica. Possibilitada a partir das anotações realizadas na fase de leitura dos trabalhos visando a futuras comparações e síntese dos resultados.

O fluxo de seleção dos trabalhos é explicitado na Figura 2. Nota-se que não foram incluídas na figura as fontes de dados nas quais não houve retorno nas buscas pelas palavras-chave indicadas.

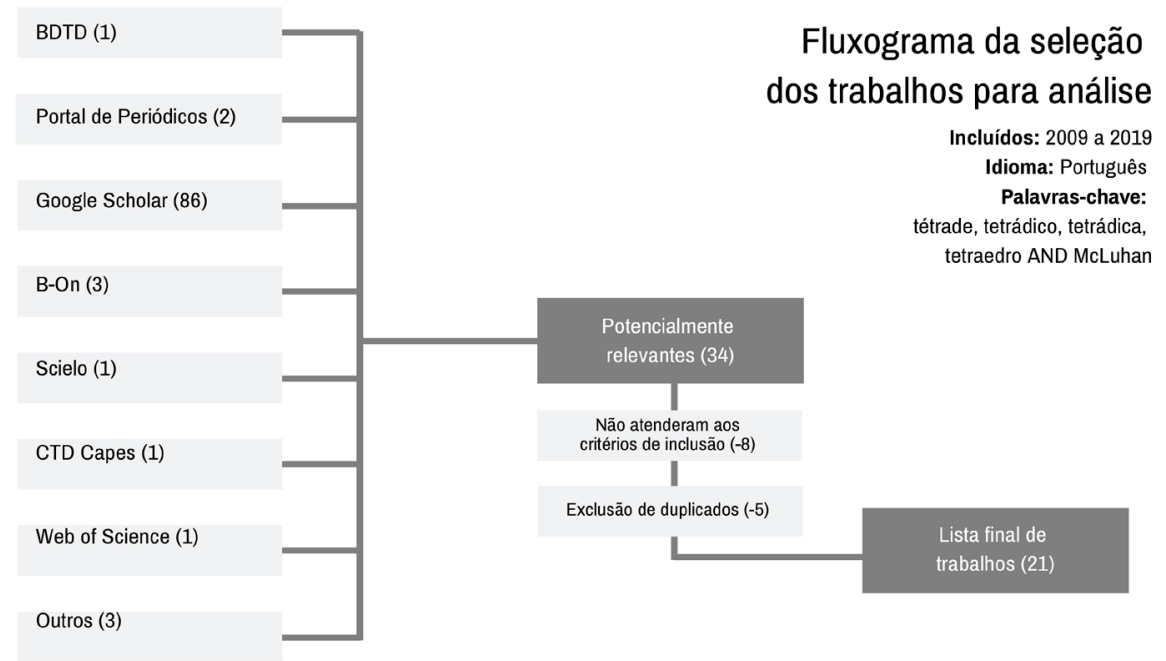

Figura 2. Fluxograma da seleção dos trabalhos para análise. Pesquisa realizada em maio de 2019.

O item seguinte trata do último passo da segunda fase de condução da revisão sistemática (Kitchenham, 2004), a síntese. Essa atividade envolve a comparação dos trabalhos selecionados e o resumo dos resultados, combinando descrição e dados quantitativos.

\section{SÍNTESE DOS RESULTADOS}

Nos 21 trabalhos analisados, identificou-se um uso variado da tétrade, tanto como ferramenta de análise de tecnologias, plataformas e meios de comunicação como de noções e conceitos. Um resumo da composição da amostra pode ser observado na Figura 3. As redes sociais, especificamente o Facebook, foram o tema mais frequente (Ghisleni \& Barichello, 2013; Patrão, 2015; Pereira, 2015a, 2015b). Seguem-se os dispositivos móveis/interfaces mobile (Alves, 2017; Oliveira, 2017), aspectos do cinema (Monteiro, 2014; Oliveira Filho \& Ribeiro, 2011), 
memes na internet (Regiani, 2017; Regiani \& Borelli, 2015) e plataformas educacionais (Patrão, 2015; Patrão \& Figueiredo, 2015).

Outras aplicações foram: projeto gráfico de jornal (Machado, 2015), comunicação interna digital (Costa \& Miguel Neto, 2017), digitalização (Stangl, 2016), tecnologia em rede (Abreu, 2014), televisão no ciberespaço (Capanema \& França, 2013), sistema baseado em localização (Reino, 2015), ferramenta jornalística de monitoramento de dados (Dall'Agnese \& Barichello, 2019) e o uso do drone para a narrativa audiovisual (Pessoa \& Gosciola, 2019).

Exemplo de aplicação a conceitos/noções/teorias, Nakagawa (2015) resgata a tétrade para situar a relação entre clichê e arquétipo - tema de outra obra de McLuhan (McLuhan \& Watson, 1970) -, a fim de delinear os aspectos que caracterizariam uma epistemologia dos meios a partir de McLuhan. Já entre as aplicações a plataformas de mídia, destaca-se a análise do Facebook por Pereira (2015a). O autor salienta que a utilização da tétrade como estratégia de exploração do Facebook busca, além de iluminar um aspecto fundamental da cultura contemporânea, "resgatar um momento da obra de McLuhan ainda pouco debatido, apostando que ali se pode encontrar uma perspectiva original e fecunda para a investigação de objetos tecnológicos e midiáticos” (p. 536).

\section{Composição da amostra}
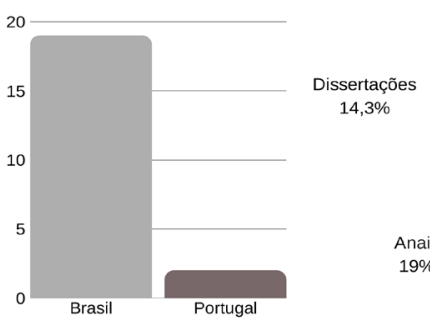

Publicações por ano

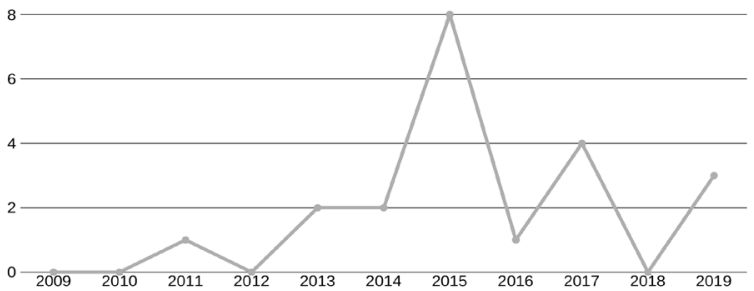

\section{Aplicações}

identificadas

- Redes sociais: Facebook (4)

- Aspectos do cinema (2)

- Dispositivos móveis/

interfaces mobile (2)

- Memes na internet (2)

- Plataformas educacionais (2)

- Clichê e arquétipo (1)

- Comunicação interna digital

(1)

- Digitalização (1)

- Ferramenta jornalística de

monitoramento de dados (1)

- Projeto gráfico de jornal (1)

- Sistema baseado em localização (1)

- Tecnologia em rede (1)

- Televisão no ciberespaço (1)

- Uso do drone na narrativa

audiovisual (1)

Figura 3. Resumo dos dados extraídos a partir dos trabalhos selecionados. Pesquisa realizada em maio de 2019. 
São identificados, ainda, casos de adaptações realizadas a fim de atender objetivos específicos de pesquisa. Silveira (2019) se baseia na tétrade para propor modelo próprio, no qual os quatro operadores transformam-se em: escreve, descreve, reescreve e des-escreve. Nesse caso, a tétrade é adaptada ao que o autor chama de Teoria Alemã da Mídia: em vez de apontar para "os efeitos que a emergência de uma nova mídia causava sobre as outras existentes na mesma ecologia midiática", como fez McLuhan, Silveira sugere que a eclosão de teorias provoca "tensões nessas 'ecologias teóricas' epistemológicas" (pp. 25-26).

Já Dall'Agnese e Barichello (2019) propõem uma adaptação no contexto do estudo do jornalismo no ecossistema midiático digital. As quatro faces, neste caso, referem-se a indicadores de possíveis reconfigurações das práticas, processos e produtos jornalísticos: adaptação, inovação, manutenção e ruptura. As autoras observam que, por meio do contraste de aspectos atuais e anteriores, a tétrade é útil para apontar tendências, transformações consolidadas ou em curso, reconhecendo que nenhuma mudança é isolada.

A presença de reflexão sobre a tétrade enquanto ferramenta metodológica nas pesquisas em comunicação, ou mesmo de apontamentos acerca das potencialidades e limites a partir das aplicações, foi verificada em apenas cinco dos 21 trabalhos (Abreu, 2014; Alves, 2017; Dall'Agnese \& Barichello, 2019; Pereira, 2015a, 2015b). Nesses, destaca-se o caráter exploratório e de complementaridade a outros métodos e técnicas de investigação.

Abreu (2014) entende que a tétrade "não elimina outros exames, críticas e apreciações" (p. 9), incluindo o desenvolvimento das ideias que sintetiza. $\mathrm{Na}$ visão de Pereira (2015a), o resultado da exploração a partir das leis da mídia são mais pistas para a investigação a ser percorrida do que respostas rígidas acerca do objeto de estudo. Em seu trabalho, propõe que uma etapa de descrição preceda a construção das tétrades:

propõe-se que antes de se lançar às dinâmicas das tétrades, uma etapa anterior da investigação tente apreender o objeto tecnológico no que toca às suas características, dinâmicas e lógica de funcionamento. Esta etapa deve ser empreendida a partir da coleta do maior volume de dados possível sobre o objeto a ser investigado. (p. 540)

Levando em conta os aspectos verificados nessa primeira etapa, a segunda parte do percurso investigativo, de aplicação propriamente dita, é definida pelo autor como um momento aberto de exploração e de "reflexões e intuições não necessariamente objetivas, mas que, por sua vez, poderão ajudar a revelar movimentos futuros de uma dada tecnologia" (Pereira, 2015a, p. 548). 
Nessa mesma linha, Dall'Agnese e Barichello (2019) afirmam que a definição do contexto micro (organizacional) ou macro (institucional) a partir do qual se tem como intuito analisar processos, práticas e/ou produtos jornalísticos objetos da investigação é fundamental para guiar a composição das tétrades. Ademais, interpretam a tétrade como possível ferramenta articuladora de dados coletados ao longo de uma pesquisa mais ampla, contribuindo para o estudo do jornalismo de forma ecossistêmica.

Alves (2017) destaca as "tétrades de efeitos midiais" como ferramentas propícias a estudar as convergências e hibridizações da contemporaneidade, em que se demandam métodos do tipo "que não limite, mas, ao contrário, aumenta, estenda ou, heuristicamente, descortine horizontes" (p. 46). Na sequência, conclui que, com as tétrades, há uma ampliação das possibilidades interpretativas na análise de distintas interfaces, "uma vez que não se considera tão-somente mudanças introduzidas no aparelho, mas as transformações psicossociais e culturais que a induzem" (p. 49).

Por outro lado, uma possível incompreensão foi verificada no texto de Machado (2015), quando este observa, em sua análise da arquitetura de uma página de jornal online, que "não parece haver exemplos de meios que foram levados ao limite" (p. 107). McLuhan e McLuhan (1988) sublinham que a tétrade "apresenta não um processo sequencial, mas sim quatro simultâneos. Todos os quatro aspectos são inerentes a cada artefato desde o início" (p. 99). Enquanto complementares e inerentes a qualquer tecnologia, meio ou artefato, o exercício tetrádico não trata de buscar diferentes objetos para ilustrar cada uma das faces, mas, sim, analisar um objeto a partir das quatros dimensões.

Nota-se que a referência feita aqui à aplicação do modelo tetrádico ou à construção ou composição das tétrades não implica necessariamente sua representação gráfica, mas a discussão de objetos (sejam teóricos, sejam empíricos) a partir das quatro leis da mídia. Dos trabalhos analisados, apenas seis apresentavam a análise em forma de figura ou tabela em quatro partes (Alves, 2017; Costa \& Miguel Neto, 2017; Dall'Agnese \& Barichello, 2019; Patrão, 2015; Patrão \& Figueiredo, 2015; Silveira, 2019).

Por fim, destaca-se a questão das variações de tradução, aspecto que foi percebido durante a revisão sistemática. Uma vez que Laws of media (McLuhan \& McLuhan, 1988) e The global village (McLuhan \& Powers, 1989/1992) não tiveram, até então, edições publicadas em português, não há um consenso acerca da melhor forma de traduzir certos termos para essa língua. Às amplas possibilidades de tradução livre somam-se as variações presentes nas duas obras. As perguntas que baseiam as leis da mídia, por exemplo, apesar de manterem as ideias principais, são elaboradas de formas distintas ao longo dos capítulos das duas publicações. 
O próprio modelo é nomeado de múltiplas formas, razão pela qual se justifica nossa opção de palavras-chave. Nos trabalhos selecionados aqui, aparecem: modelo tetrádico (Oliveira, 2017); tétrade dos efeitos midiais (Alves, 2017); tétrade dos efeitos de mídia McLuhaniana (Silveira, 2019); teoria tetrádica de McLuhan (Ghisleni \& Barichello, 2013); modelo de tétrade para análise dos efeitos dos media (Patrão \& Figueiredo, 2015); tétrade de Laws of media (Monteiro, 2014); e tetraedro (Oliveira Filho \& Ribeiro, 2011).

Quanto aos quatro componentes, a maior quantidade de variações de tradução se refere aos verbos da primeira face da tétrade, enhancement. Foram encontrados: acentua (Alves, 2017; Patrão \& Figueiredo, 2015); amplia (Abreu, 2014); amplifica (Pessoa \& Gosciola, 2019); aperfeiçoa (Reino, 2015); aumenta (Nakagawa, 2015); estende (Costa \& Miguel Neto, 2017; Ghisleni \& Barichello, 2013; Monteiro, 2014; Regiani, 2017); incrementa (Pereira, 2015a); intensifica (Alves, 2017; Pessoa \& Gosciola, 2019); melhora (Regiani, 2017); potencializa (Alves, 2017; Pereira, 2015a, 2015b); e realça (Patrão \& Figueiredo, 2015).

Nas demais, é unânime a tradução de retrieval como recuperação (de algo tornado obsoleto) e de reversal como reversão, exceto por poucas variantes: transformação (Alves, 2017; Monteiro, 2014) e inversão (Nakagawa, 2015). Por fim, obsolescence traduz-se na maioria dos trabalhos como "obsolescer" ou "tornar obsoleto", mas, também, como "condenar ao desuso" ou "pôr fora de moda" (Alves, 2017).

\section{APONTAMENTOS FINAIS}

A revisão sistemática da literatura possibilitou um mapeamento de 21 aplicações da tétrade de McLuhan em trabalhos da área de comunicação desenvolvidos na última década no Brasil e em Portugal. Os exemplos demonstraram a amplitude de possíveis usos e o potencial da ferramenta para abordar fenômenos complexos, software ou hardware, sempre em relação ao contexto em que tecnologias ou teorias surgem e estão situadas na sociedade.

$\mathrm{Na}$ pesquisa acadêmica, podemos considerar como contexto (ou fundo) primordial o olhar comunicacional, que permite apreender um objeto empírico (seja uma tecnologia, produto, prática, processo) como um objeto do conhecimento da comunicação (França, 2016). Adiciona-se, ainda, o background teórico que fundamenta cada pesquisa em particular. Essas noções, misturadas com a percepção individual de pesquisadoras e pesquisadores, vão definir o que será visto e questionado ao objeto da tétrade. Portanto, mesmo que análises dos quatro processos (enhancement, obsolescence, retrieval, reversal) sejam construídas a partir dos mesmos objetos empíricos, não teremos, em diferentes pesquisas, tétrades iguais. 
Por essa razão, é importante que o caminho percorrido (de observação, de revisão teórica, de coleta de dados) até a construção da tétrade fique claro no relatório de pesquisa. Esse movimento é destacado, por exemplo, por Pereira (2015a, 2015b) ao propor uma etapa descritiva antes da aplicação da tétrade. Igualmente relevante é evidenciar a filiação do modelo, que é, antes de tudo, uma síntese da carreira de McLuhan, de suas ideias principais. Isso é efetivado em alguns dos trabalhos selecionados a partir de revisões teóricas de fôlego (e.g., Nakagawa, 2015; Oliveira Filho \& Ribeiro, 2011; Pereira, 2015a, 2015b; Pessoa \& Gosciola, 2019; Stangl, 2016).

Quanto às potencialidades, o caráter de "sonda exploratória" (evidenciado pelo próprio McLuhan e reforçado nos trabalhos analisados) da tétrade pode ser útil em diversos momentos, seja para aguçar a percepção na formulação de um problema ou mesmo para articular dados coletados ao longo de uma pesquisa. O exercício pode ser repetido à medida que a investigação avança e/ou que são verificadas mudanças no contexto analisado. Como resultado, podem ser criadas tétrades individuais ou grupos de tétrades interconectadas.

Ao convidar à análise de um objeto sempre em relação a outros, o modelo tetrádico coloca meios, tecnologias e artefatos em perspectiva e permite comparações ao longo do tempo. A tétrade da televisão nos anos de 1960, por exemplo, pode basear a construção da tétrade sobre a atual TV digital. Se levarmos em conta, ainda, que as mudanças nas tecnologias de informação e comunicação nunca são isoladas, um conjunto de tétrades com diferentes objetos de análise pode ser mais esclarecedor para compreender transformações gerais da sociedade em relação a um meio em particular. Ou até mesmo para apresentar um panorama das mutações de mídia ao longo dos tempos.

Por outro lado, esse caráter exploratório da tétrade também pode ser apontado como uma de suas principais limitações enquanto ferramenta de pesquisa. Trata-se de uma forma interessante para organizar percepções acerca de um objeto - enquanto exercício de abertura, e não de fechamento. Portanto, é útil como uma das componentes do ferramental teórico-metodológico de uma pesquisa, mas não suficiente para tirar conclusões em uma investigação mais ampla.

Tendo em vista o pequeno número de trabalhos que efetivamente aplicou o modelo, um obstáculo à difusão da tétrade pode residir na complexidade do exercício exigido pela ferramenta, que demanda um olhar para aspectos complementares e contraditórios de um objeto de estudo. Como destacou Levinson (1999), já mencionado aqui, a tétrade desafia o intelecto e a imaginação a compreender os efeitos latentes das mídias no cotidiano. Para isso, envolve: a observação das características de um meio no tempo atual; o estudo daquilo que o antecedeu e/ou originou; e até especulações sobre cenários futuros. Soma-se à 
essa complexidade a vastidão de resultados possíveis: um só objeto pode gerar várias tétrades, quanto mais revisões forem feitas.

A amplitude da própria noção de medium e as tantas interpretações de outras categorias e metáforas constantes na obra de Marshall McLuhan também podem ser entraves para o uso da tétrade enquanto ferramenta de pesquisa pelos estudos em comunicação. Apesar de Laws of media (McLuhan \& McLuhan, 1988) e The global village (McLuhan \& Powers, 1989/1992) trazerem, juntos, dezenas de exemplos de aplicação, as quatro leis da mídia são teoricamente pouco desenvolvidas, o que pode gerar dificuldades na identificação dos aspectos a serem apontados em cada uma das partes.

Nesse sentido, novas discussões, desenvolvimentos e até adaptações da tétrade seriam interessantes para ampliar seu alcance entre as pesquisas em comunicação. Até então, levando em conta os trabalhos que compuseram esta revisão, a adoção do modelo enquanto ferramenta metodológica pela área parece incipiente e carente de problematização. Quanto a propostas de adaptação das faces da tétrade, somente duas foram verificadas (Dall'Agnese \& Barichello, 2019; Silveira, 2019).

Além disso, a variedade de traduções para a língua portuguesa, em especial pela ausência de uma nomenclatura única para o modelo, pode dificultar a identificação e o agrupamento de trabalhos similares. Dessa forma, não descartamos que muitas outras aplicações não abrangidas por nossas palavras-chave e critérios de busca possam ser verificadas na literatura disponível.

Futuramente deverão ser efetuadas revisões em outros países, períodos e línguas - incluindo a original das publicações, o inglês. O protocolo e os passos seguidos aqui podem ser um ponto de partida para futuros esforços nesse sentido. $\mathbf{M}$

\section{REFERÊNCIAS}

Canavilhas, J. (2010). O novo ecossistema mediático. Recuperado de https://bit.ly/ 2Yc2L6X

França, V. V. (2016). O objeto e a pesquisa em comunicação: Uma abordagem relacional. In C. P. Moura \& M. I. V. de Lopes (Eds.), Pesquisa em comunicação: Metodologias e práticas acadêmicas (pp. 154-174). Porto Alegre, RS: EdiPUCRS, 2016.

Kitchenham, B. (2004). Procedures for performing systematic reviews (Technical report). Recuperado de http://www.inf.ufsc.br/ aldo.vw/kitchenham.pdf

Levinson, P. (1999). Digital McLuhan: A guide to the information millennium. Londres, Inglaterra: Routledge. 
Logan, R. (2011). Figura/Fundo: Decifrar o código McLuhan. E-Compós, 14(3), 1-13. doi: 10.30962/ec.v14i3.709

McLuhan, M. (2005). Address at vision 65. In E. McLuhan \& F. Zingrone (Eds.), Essential McLuhan (pp. 219-32). Londres, Inglaterra: Taylor \& Francis.

McLuhan, M. (2007). Os meios de comunicação como extensões do homem (3a ed.). São Paulo, SP: Cultrix. (Obra original publicada em 1964)

McLuhan, E., \& McLuhan, M. (1988). Laws of media: The new science. Toronto, Canadá: University of Toronto Press.

McLuhan, E., \& McLuhan, M. (2017). The lost tetrads of Marshall McLuhan. Nova York, NY: OR Books.

McLuhan, M., \& Powers, B. (1992). The global village: Transformations in world life and media in the 21st century. Oxford, Inglaterra: Oxford University Press. (Obra original publicada em 1989)

McLuhan, M., \& Watson, W. (1970). From cliché to archetype. Nova York, NY: Viking.

Meyrowitz, J. (2003). Canonic anti-text: Marshall McLuhan's Understanding media. In E. Katz, J. D. Peters, T. Liebes, \& A. Orloff (Eds.), Canonic texts in media research (pp. 191-202). Cambridge, Inglaterra: Polity Press.

Petticrew, M., \& Roberts, H. (2006). Systematic reviews in the social sciences: A practical guide. Oxford, Inglaterra: Blackwell.

\section{TRABALHOS QUE COMPUSERAM A REVISÃO SISTEMÁTICA}

Abreu, P. (2014, novembro). McLuhan e a estética da convergência: Aproximações, debates e novas possibilidades comunicacionais. Recuperado de https:// bit.ly/2UuuDRH

Alves, T. A. (2017). De máquinas aos meios de comunicação: Como interfaces auxiliam no processo de apreensão de novos aparelhos multimidiáticos (Dissertação de mestrado). Recuperado de https://bit.ly/3fOyZM8

Capanema, L., \& França, R. (2013). A televisão no ciberespaço: Reformulações da televisão na internet e na TV digital. Revista Geminis, 4(1), 20-36. Recuperado de https://bit.ly/39m84mh

Costa, J., \& Miguel Neto, P. (2017). Organitelling: Uma proposta de utilização das TICs na comunicação interna. CઐS, 39(2), 259-284. doi: 10.15603/2175-7755/ cs.v39n2p259-284

Dall'Agnese, C. T. W., \& Barichello, E. M. N. R. (2019). A tétrade mcluhaniana como método para investigar as reconfigurações do jornalismo no ecossistema midiático. Revista Famecos, 26(1), 1-21. doi: 10.15448/1980-3729.2019.1.30928 
Ghisleni, T., \& Barichello, E. (2013). Ecologia das mídias nas redes sociais digitais: estendendo a Teoria Tetrádica de McLuhan ao estudo do Facebook. In E. M. M. R. Barichello \& A. Rublescki (Eds.), Ecologia da Mídia (pp. 79-98). Santa Maria, RS: Facos-UFSM.

Machado, R. (2015). Técnica e audiovisualidades: Arquitetura de informação e a emergência do homem na tecnocultura (Dissertação de mestrado). Recuperado de http://www.repositorio.jesuita.org.br/handle/UNISINOS/3768

Monteiro, A. (2014, dezembro). A imagem pós-McLuhan e Baudrillard: Metáforas de opostos. Recuperado de https://bit.ly/2UK0Bbr

Nakagawa, R. (2015). Os ambientes e os contra-ambientes: Uma possível epistemologia dos meios. Comunicação Midiática, 10(1), 41-54. Recuperado de https://bit.ly/39sjAwH

Oliveira, V. (2017). Jornalismo em dispositivos móveis: Uma concepção estratégica de conteúdos noticiosos para tablets e smartphones (Tese de doutorado). Recuperado de https://repositorio.unb.br/handle/10482/31973

Oliveira Filho, W., \& Ribeiro, L. (2011). McLuhan e o live cinema: A tela desconstruindo a mensagem. EcoPós, 14(3), 89-104. doi: 10.29146/eco-pos. v14i3.909

Patrão, C. (2015). A educação de uma nova geração de jornalistas: Do Moodle ao Facebook (Tese de doutorado). Recuperado de https://bit.ly/3crWM2i

Patrão, C., \& Figueiredo, A. (2015). Participação e exposição, consciência e competência: Os contornos de uma estratégia pedagógica para o ensino do jornalismo. In S. Gonçalves, H. Almeida, \& F. Neves (Eds.), Pedagogia no ensino superior (pp. 188-208). Coimbra, Portugal: Cinep-IPC.

Pereira, V. A. (2015a). Como antecipar os efeitos de uma tecnologia? Um modelo exploratório inspirado na Nova Ciência de McLuhan e aplicado ao Facebook. Intexto, (34), 535-552. doi: 10.19132/1807-8583201534.535-552

Pereira, V. A. (2015b, junho). Como antecipar os efeitos de uma tecnologia? Um modelo exploratório inspirado na nova ciência de McLuhan e aplicado ao Facebook. Recuperado de https://bit.ly/2JmbYkE

Pessoa, L., \& Gosciola, V. (2019, abril). Drone no âmbito audiovisual contemporâneo: Uma perspectiva de Marshall McLuhan. Recuperado de https:// bit.ly/2T4dOfr

Regiani, H. (2017). Memetizando e midiatizando: Memes como estratégia discursiva evangélica (Dissertação de mestrado). Recuperado de https://bit.ly/2Z4VtCy

Regiani, H., \& Borelli, V. (2015). Memes de internet na Ecologia da Mídia: Entre metáforas e teorias. Lumina, 9(2), 1-17. doi: 10.34019/1981-4070.2015.v9.21226 
Reino, L. (2015). Jornalismo baseado em localização: Uma análise das potencialidades na produção e no consumo de notícias (Tese de doutorado). Recuperado de http://repositorio.pucrs.br/dspace/handle/10923/7814

Silveira, M. T. (2019). Teoria alemã das mídias: Mídia, história, cultura e técnica no território comunicacional alemão (Tese de doutorado). Recuperado de https://www.lume.ufrgs.br/handle/10183/193378

Stangl, A. (2016). Modos de coexistência mediada: Por uma ontologia da atenção distribuída digitalmente (Tese de doutorado). doi: 10.11606/T.27.2017. tde-20022017-150757

Artigo recebido em 21 de julho de 2019 e aprovado em 25 de março de 2020. 
